\title{
The Analysis on Discount Phenomenon of Convertible Bonds
}

$$
\text { Huahong Yan }{ }^{1, a} \text { and Yezi Fang }{ }^{2, b}
$$

${ }^{1}$ School of Accounting, University Capital University of Economics and Business, Beijing 1000070, China;

${ }^{2}$ School of Accounting, University Capital University of Economics and Business, Beijing 1000070, China.

$$
\text { a1159153472@qq.com, bxnzxfyz@163.com }
$$

\begin{abstract}
With the continuous development of China's capital market, there are more and more new financing tools coming out in the market. This paper aims at discover the convertible bonds theory value of China's market by analyzing the terms of the convertible bonds and factors which can influence value and combing with the characteristic of the convertible bonds market in our country. Then this paper chooses Tsiveriotis and Fernandes model and use binary tree calculation method at the same time to calculate 102 convertible bonds listed in the market since 2002-2015, and find out the convertible bonds theory values are higher than actual values, then we put forward policy Suggestions.
\end{abstract}

Keywords: Convertible bonds; T-F Binary tree model; Theory-Price; Issuing price; Discount phenomenon.

\section{可转换债券发行折价现象分析}

\author{
间华红 ${ }^{1}$, 方叶子 ${ }^{2}$
}

（1. 首都经济贸易大学会计学院 北京 $100070 ； 2$. 首都经济贸易大学会计学院 北京 100070)

摘要: 随着我国资本市场的不断发展以及近年来股市的震荡加剧，可转换债券受到了越来越多投资者的青睐。市场上对 可转债的价值问题十分关注，准确的定价对于可转债的发行以及可转债市场的良好发展有着十分重要的意义。基于此，首先 针对可转债的定价模型进行选择分析, 结合我国可转债市场的相关特点, 选取了 Tsiveriotis 和 Fernandes (1998) 模型并 采用二叉树的数值计算方法; 对我国自 2002 年-2015 年发行的 102 只可转换债券的发行时点的理论价格进行计算, 计算结 果显示我国可转债发行价格与理论价格普遍存在了大幅度的折价现象; 最后对可转债的发行折价现象进行分析, 并提出相关 建议。

关键词: 可转换债券; T-F 二叉树模型；理论价格；发行价格；折价现象

中图分类号: F830.91 文献标志码: A

引言

我国第一支上市可转换债券于 1993 年 2 月 10 日由宝安公司发行，历经 20 多年的发展，截止到 2015 年底, 我国的可转债存量已达到 118.74 亿元。经济和市场的繁荣促进了可转债的发展, 对于可转债的研 究也更具有现实意义, 其中最受关注的当属可转债的定价理论和模型的研究。由于可转债条款设计复杂并 存在债券和期权叠加的特性, 使其价格难以确定, 因此中外学者对此付出了大量研究, 设计出适合各种情 况的可转债定价理论, 近年来中国股市有了较大的波动, 可转换债券市场也随之有了较大的发展。但由于 可转换债券在我国发展时间较短, 国内的许多研究都是基于国外的研究成果而建立的, 缺乏大量实践的验 证; 并且随着近几年可转债市场的恢复和逐渐发展, 我国可转债累计发行数量已有 114 只, 鉴于此, 本文 
对我国可转债的定价进行研究, 考察可转债市场的发行时点其发行价格与理论价格的一致性情况, 并进一 步验证我国可转债发行是存在折价或溢价, 本文选取截止 2015 年 12 月 31 日以前所有上市发行的可转换 债券为样本, 丰富了可转债的研究数据, 着重研究可转债发行时点的价值情况, 对可转债的发行价值进行 计算, 旨在为可转债的市场监管者完善市场、发行方合理定价和投资者选择提供参考。

\section{1 可转债定价模型的选择}

\section{1 模型的选择}

历经国内外学者数十年的研究之后, 对于可转债的定价模型理论已经比较成熟。其中最被认可且应用 最为广泛的为 B-S 模型和引入信用风险的二叉树模型。在我国对于可转换债券价值的相关研究中, 大量文 献采用了 B-S 模型计算可转债的理论价格, 但是通过对比 B-S 模型的适用条件发现, 它与我国可转债市场 的实际情况并不相符，本文选择 T-F 二叉树模型对我国上市可转债进行定价，具体原因如下：

二叉树方法能灵活地处理欧式期权和美式期权的定价问题, 适用于我国可转债的转股期权特征: (1)T-F 模型将可转换债券分为股权部分和债券部分, 对于股权部分采用无风险利率折现, 债券部分采用含有信用 风险的调整后利率折现。我国证券市场偏向于股权融资, 股票市场上几乎没有违约风险, 而债券则可能会 面对无力偿还的违约风险, 符合我国证券市场特点; (2) T-F 模型中对于信用利差的选取采用常值, 这符合 我国市场的特征, 由于发行条件严格, 我国可转债的信用评级较高, 多为 AA 级以上, 而且期限较短, 大 多在 5-6 年间, 可以认为我国可转债的信用利差为常值; (3)我国可转债市场规模小, 可以适应二叉树模型 的过程繁琐, 计算量大的特点。截止 2015 年底累计 113 只可转债发行上市, 计算量在可以接受的范围内, 也比较适合我国可转债市场的定价计算。

通过以上分析和比较, 本文认为引入信用风险的可转债二叉树定价模型更加适合我国市场的特点, 其 中 Tsiveriotis 和 Fernandes (1998) 的 T-F 二叉树模型方法最为适合。

\section{1. $2 \mathrm{~T}-\mathrm{F}$ 二叉树定价模型的构建}

首先建立标的股票的二叉树模型，取当前股票价格作为初始起点，并采用固定的股价波动率计算出每 一个节点的股票价格; 其次计算可转债在到期日的价格，按照到期日的终端条件对到期日节点进行价值判 断, 选取转股价值与债券本息合计中的较大值; 然后设定可转债转股的概率, 如果转股价值大于债券到期 日本息和, 则转股概率为 1 , 否则, 转股概率为 0 ; 随后从到期日的每个节点开始, 向前依次递推, 按照 需要满足的边界条件对每一个节点的可转债价值进行处理和判断, 并选择适当的折现率进行折现, 从而求 出可转债价格。可转债节点定价的通用公式可以表示为:

其中: 为节点 $(i, j)$ 的可转债价值; 为 $i$ 时刻的转换比率; 为 $(i, j)$ 节点处的标的股票价格; 和 分别为 $i$ 时刻的回售价格和赎回价格；为 $(i, j)$ 处的持有价值，可以用以下公式计算得到：

其中: 和分别表示 $(i, j)$ 节点的下一时刻上升点和下降点的可转债价值; 和表示 $(i, j)$ 下一时刻 上升点和下降点的调整后贴现率, 其计算公式为:

其中: 为无风险利率; 为信用风险利差; $p$ 为该节点处的转股概率, 如果发生转股, 则 $p=0$, 否则, $p=1$ 。

另外, 在模型的具体操作过程中, 需要对参数进行具体的估计和计算。在计算标的股票的股价波动率 时, 本文选取在可转债上市前 180 天内的股票日收盘价计算其每日波动率，年化处理时以每年 252 个交易 
日计算; 在估计无风险利率时, 本文首先自 wind 数据库中导出历年来发行的国债基本情况, 根据每只可 转债的发行时间和存续期限，找出对应或近似的国债利率，以此作为无风险收益率; 在考虑信用风险利差 时, 本文自 wind 数据库中导出历年发行的所有企业债券, 按照可转债的信用评级、发行时间和存续期限, 找出对应或近似的企业债券的到期收益率。将企业债券到期收益率与其所对应的无风险利率之差作为该可 转债的信用风险利差; 二叉树的步数按照以往研究的经验来讲, 通常将 3-5 年期的可转债存续期分为 200 个时间段, 可以得出较为准确的结果; 赎回价格、回售价格、转股价格等参照可转债发行时的相关条款规 定确定。

\section{2 可转债的理论价格计算及分析}

\section{1 理论价格的确定}

截至 2015 年 12 月 31 日，在我国沪深证券交易所上市的可转换债券共有 114 只。本文将这些可转债 全部纳入样本范围内，并按照以下条件进行笁选：剔除含有极端条款的可转债；剔除由于时间久远或近期 发行造成数据不全或无法获得的可转债。经过剔除, 最终保留了 102 只可转债作为本文的实证检验样本。 样本时间范围跨度 13 年, 涉及多家行业, 包括沪市 64 只, 深市 38 只。本文样本数据来自国泰安数据库、 wind 数据库、巨潮网以及沪深两大证券交易所。本文在计算可转债的理论价格时, 采用 Matlab 软件并借 鉴 Tsiveriotis 和 Fernandes（1998）定价模型的二叉树方法编写成函数, 然后带入每只可转债的相关变 量用以计算每只上市发行可转债在发行日期当天的理论价值。我国可转债发行价格均为 100 元，而通过计 算结果发现，所有样本可转债在上市日期的理论价格均高于发行价格，证明我国市场的可转债在发行时确 实存在价值偏离现象, 且明显为发行折价。

\section{2 折价现象分析}

为了衡量市场折价现象的程度, 本文假设每只可转债发行折价率为 1ow, 并通过理论价格和发行价格 计算折价幅度的大小，计算公式如下：

其中: 为第 $i$ 只可转债的发行价格; 为第 $i$ 只可转债的发行日理论价格。

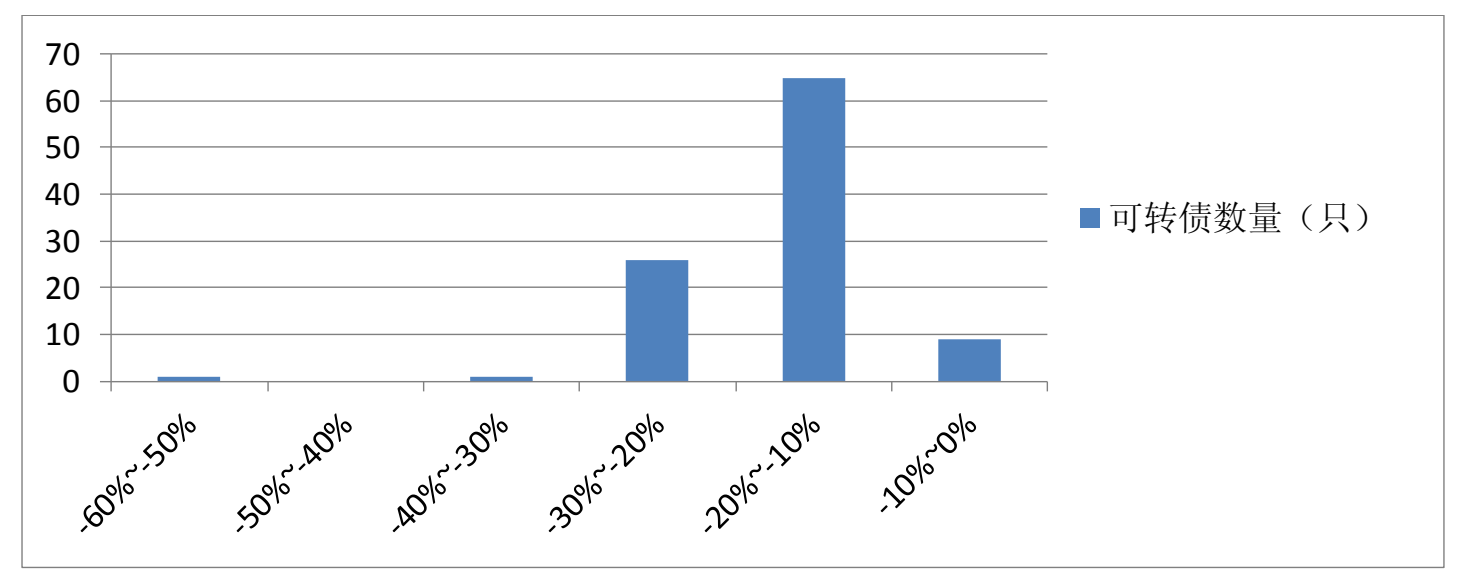

按照上述公式计算可以得到每只可转债的折价幅度得出：所有样本可转债的折价率均为负数，负号表 示市场价格低于理论价格, 即存在明显的折价现象。而单从折价的程度上来讲, 我们对 low 值做绝对值处 理后，发现最大为 $54.61 \%$, 最小的也有 $5.19 \%$ ，有 28 只可转债的折价率绝对值达到了 $20 \%$ 以上。将 
所有可转债样本折价率的绝对值作平均, 得出平均数 $17.09 \%$, 中位数 $16.34 \%$ 。分布范围统计如图 1 所示, 折价率大多集中在 $-30 \%-10 \%$ 之间, 共有 91 只; 另有 9 只折价程度较低, 10 值分布在 $-10 \%-0$ 之间。图 1 可 转债折价幅度分布情况

在一级发行市场, 可转债有明显的折价现象, 最直观的就是其发行价格低于理论价格。如果我们假设 理论定价模型合理并且适用, 那么理论价格能够真实反映可转债的内在价值。我国市场规定, 可转债的发 行价格统一为 100 元, 但这并不是由可转债市场上买卖双方博亦的结果, 不能代表真实的市场价格。由此 可以发现，不同于可转债存续期内的折价现象，发行时期的折价率中不仅包含市场实际价格对于可转债的 偏差率，还包含了由发行规定造成的发行价格与真实市场价格的偏差率。两者之和共同构成了发行时的折 价率。在此, 本文将发行价格与理论价格的偏离率定义为发行总偏差率，发行价格与市场价格的偏差率定 义为发行偏离率，市场价格与理论价格的偏差率定义为市场偏差率。发行价格与市场价格存在偏差意味着 发行定价失效或低效, 而市场价格与理论价格偏差率意味着市场定价失效。本文采用可转债上市首日的收 盘价作为发行时期的市场价格进行研究, 假设发行价格与市场价格偏差率为, 市场价格与理论价格偏差率 为，这两个变量可以用以下公式来表示：

其中: 即为可转债上市首日收盘价。

本文自 wind 数据库截取前文所述样本的上市首日收盘价, 按照上述公式计算得到 $D F$ 和 $D M$ 的值, 经 计算, 全部可转债的 $D F$ 平均值为 $-12.67 \%, D M$ 平均值为 $-4.42 \%$ 。这意味着可转债发行折价率中, 发行价格 与市场价格偏离差贡献了- $12.67 \%$, 市场价格与理论价格偏离差贡献了 $-4.42 \%$ 。由此可见, 可转债的发行 价格严重低估了市场的真实情况，投资者对于可转债的估价是高于当前发行价格的。而真实市场价格对于 理论价格低估程度的均值为 $-4.42 \%$ 。我们采用 stata 软件对 $D F$ 和 $D M$ 进行 ttest 检验, 得出 $p$ 值为 0.0007 小于 $0.05, D F$ 值显著小于 $D M$ 值。

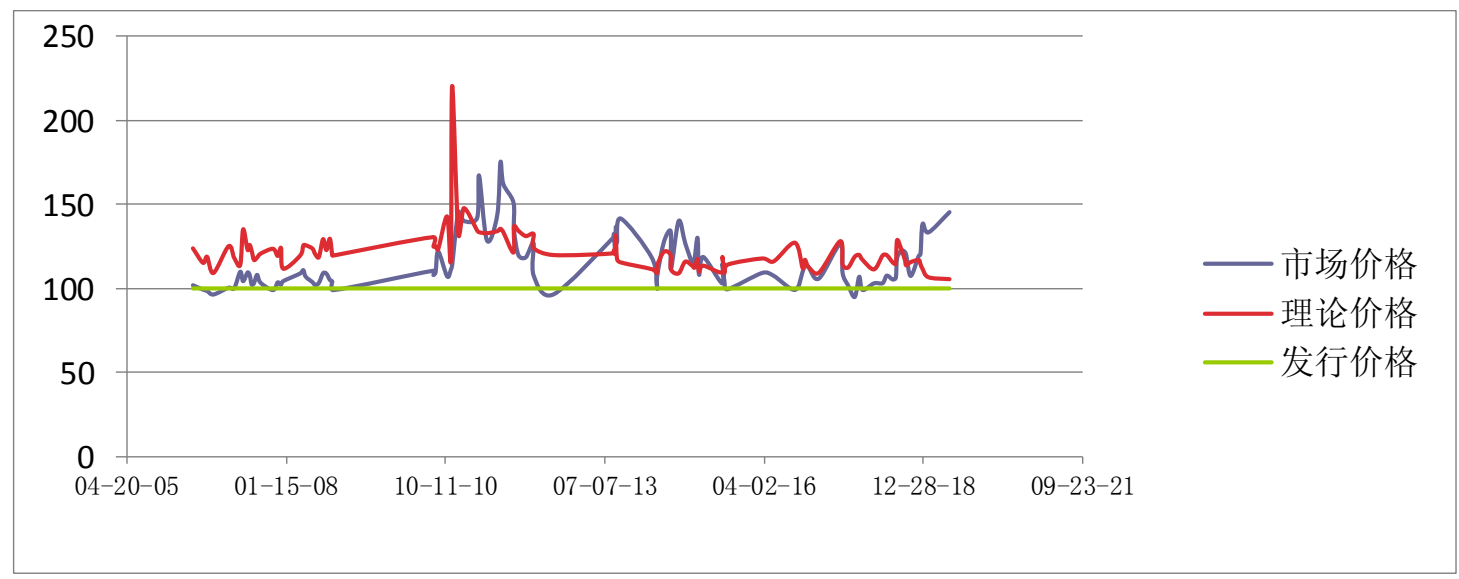

但是通过观察数据可以明显发现, 引入市场价格后, 发行价格偏离率与市场价格偏离率并不总是负值, 存在一部分发行溢价和市场溢价的现象。其中出现发行溢价现象的可转债较少, 仅有 11 只, 且溢价程度 较低, 多为 $1 \%$ 以下; 存在市场溢价情况的较多, 有 26 只可转债出现了不同程度的溢价情况, 最高为 $37.7 \%$, 属于较为严重的溢价程度。本文对可转债发行价格、市场价格和理论价格按发行时间做出趋势线，可见图 
从上图中能够直观的看出发行价格、市场价格与理论价格之间的关系。市场价格基本上都比发行价格 高, 除个别略低于发行价格的几乎可以忽略不计。理论价格多数情况下高于市场价格，在某些特殊的时期 内, 市场价格线和理论价格线交替穿插, 市场折价和溢价相继出现。出现溢价的时间段主要有三个, 2007-2008 年, 2010-2012 年和 2015 年左右,这三个时间段恰巧是我国股票市场出现较大幅度变动的时期, 股市的急剧波动使可转债的市场价格也出现了盲目的上涨和波动, 造成了市场价格比理论价格要高。此时, 市场上涌入了大量的投机者, 他们不关心证券本身的价值, 以追求买卖价差为目的进行盲目的市场操作, 进一步通过供求关系影响了证券价。可以说, 此时可转债市场价格中掺杂了很多市场因素, 并不能反映常 态下价值状况。

\section{3 结论及建议}

本文通过对整体折价率的分析对发行市场的折价现象进行了相关研究，得出本文结论如下：可转债发 行市场折价现象普遍存在。我国可转债发行市场上普遍存在发行价格低于理论价格的现象, 发行总折价率 为-17.09\%，其中发行折价率为-12.67\%，市场折价率为-4. $42 \%$ 。发行折价率体现的是发行价格对市场价格 的低估程度，是发行机构对市场投资者普遍认可的期望价格的误判，导致发行方在发行时遭受损失。而市 场折价率是市场价格对理论价格的低估程度，体现了市场对可转债定价的失效，投资者通过折价购买可转 债获得所谓的利差收益。根据以上的研究总结，我们建议相关机构完善可转债的发行市场机制。可转债的 相关法律中规定了在发行时可转债统一的面值为每张 100 元。但是, 可转债由不同公司发行, 它的价值会 因为标的股票价格和公司价值的影响从而各不相同。将这些可转债统一按照面值发行显然忽略了其各自的 市场价值，造成了发行价格定价失效，使得一些优质的发行公司承担了发行损失，而较差的发行公司反而 获得收益, 容易出现逆向选择现象。因此, 可转债的相关管理机构和立法部门应对此加以重视, 完善可转 债发行市场规定，建立合理的发行定价机制，以保护可转债发行公司的利益。

\section{参考文献：}

[1] 陈晓红，吴小瑾，彭佳. 一种新的基于公司价值的可转债定价方法 [J]．系统工程学报，2013，01:34-39.

[2] 付雷鸣,万迪昉, 张雅慧. 融资优序理论新证: 公司债、可转债和增发股票宣告效应的比较分析 [J]. 金融评论, 2011, 01:101-114+125-126.

[3] 枈朴, 赵海滨. 有限元方法在可转换债券定价中的应用 $[J]$. 武汉理工大学学报（交通科学与工程版), 2004, 02:194-196

[4] 刘大巍，陈启宏，张肿．关于我国可转债定价修正模型的实证研究 [J]。管理工程学报，2011，01:184-191.

[5] 刘娥平.中国上市公司可转含债券发行公告财富效应的实证研究 [J]. 金融研究，2005（7)：45-46

\section{References:}

[1] Chen Xiaohong, Wu Xiaojin, Peng Jia. A New Pricing Method of Convertible Bonds Based on Corporate Value [J]. Journal of Systems Engineering, 2013, 01: 34-39.

[2] Fu Leiming, Wan Dafang, Zhang Yahui. A new empirical analysis of the theory of financing priority order: a comparative analysis of corporate bonds, convertible bonds and issuance of shares [J]. Finance Review, 2011, 01: 101-114 + 125-126.

[3] Gong Pu, Zhao Haibin.Application of Finite Element Method in Pricing of Convertible Bonds [J]. Journal OF Wuhan University OF Technology (Transportation Science and Engineering), 2004, 02: 194-196.

[4] Liu Dawei, Chen Qihong, Zhang Chong.Empirical study on China's convertible bond pricing 
correction model [J]. Journal of Management Engineering, 2011, 01: 184-191.

[5] Liu Eiping.Experimental study on the wealth effect of Chinese listed companies in convertible bond issuance announcement [J]. Finance Research, 2005 (7): 45-46

[6] Ammann M, Kind A, Wilde C.2008.Simulation-based pricing of convertible bonds [J]. Journal of Empirical Finance, 15(2):310-331.

[7] Brennan M J, Schwartz E S.1980.Analyzing convertible bonds [J]. Journal of Applied Corporate Finance,:55-64

[8] Buchan M J.1997. The pricing of convertible bonds with stochastic term structures and corporate default risk [Z].Working Paper, Amos Tuck School of Business, Dartmouth College.

[9] Caraynannopoulos P. 1996. Convertible bonds pricing and inherent biases[J].The Journal of Fixed Income, 13(3):64-73

[10] Davis M, Lischka F.1999. Convertible bonds with market risk and credit default [J]. AMS IP Studies in Advanced Mathematics,26:45-58

[11] Ingersoll J E.1977.A contingent claims valuation of convertible secuties [J]. Journal of Financial Economies,4(3):289-321 